\title{
The impact of the passenger train speed on the comfort of humans in a building close to the railway
}

\author{
Filip Pachla \\ Cracow University of Technology, Cracow, Poland \\ E-mail:fpachla@pk.edu.pl
}

Received 24 August 2018; accepted 31 August 2018 DOI https://doi.org/10.21595/vp.2018.20174

Check for updates

Copyright $(2018$ Filip Pachla. This is an open access article distributed under the Creative Commons Attribution License, which permits unrestricted use, distribution, and reproduction in any medium, provided the original work is properly cited.

\begin{abstract}
The article presents the impact of the speed of a passenger train on the comfort of humans in the building. Kinematic excitations were obtained from field tests and used in numerical calculations. Numerical calculations were made on the spatial FEA model of the residential building. The WODL ratio prediction curve was determined depending on the train speed.
\end{abstract}

Keywords: railway, vibrations, HST, human comfort, FEA model.

\section{Introduction}

The development of the railway line is associated with reducing the travel time between cities. Due to restrictions on the possibility of extending the railway line (shortening the section in terms of length), the easiest way is to increase the crossing speeds. Any investment related to a change in the operating conditions of a railway line requires the preparation of previous analyzes regarding the impact of the proposed change on the environment. In particular, this concerns the impact of railway modernization on neighboring buildings. The most important issue is the impact of vibrations on people in the building. In the world literature and country standards, the impact of vibrations on people is analyzed using various methods [1-7]. The Polish standard [8] specifies the procedure for evaluation the impact of vibrations on people in such cases. The following article presents the analysis of the impact of vibrations on people from the passage of a passenger train (electric integrated traction train) with different speeds on one of the main railway lines in Poland. The simulation works presented in the following article were preceded by field tests during which the vibrations of foundations of a residential building made in traditional brick technology were determined. The recorded accelerations were used as kinematic excitations in the analysis of the 3D FEM calculation model.

\section{Field tests}

In order to identify the impact of vibration velocity on the reception of vibrations by people in the building, 15 kinematic excitations were selected. All registrations were made on one measurement day in specific ground conditions on the foundation wall of a single-family building located approximately $40 \mathrm{~m}$ from the railway line. The calculations were carried out for crossing speeds $40,80,120,160,200,230$ and $250 \mathrm{~km} / \mathrm{h}$. At the present the train speed at the line is limited to $200 \mathrm{~km} / \mathrm{h}$. It is still much lower than in other countries, where railway is more developed. In China for example the influence of high speed trains (HST) for ground borne vibrations where examine for speed up to $410 \mathrm{~km} / \mathrm{h}$ [9]. In Poland the next step in increasing the train speed for passenger trains is $250 \mathrm{~km} / \mathrm{h}$. The analyzed passenger train is presented in Fig. 1. It is an electric integrated traction train - code name Pendolino. Fig. 2 presents selected record of the vibration accelerations of the foundation at the speed of $250 \mathrm{~km} / \mathrm{h}$. Fifteen selected crossings of the train were analyzed. The assembly method of the sensors on the building's foundation is presented in Fig. 3. All three components of ground vibration acceleration for all the analyzed velocities were used as a kinematic excitation in the 3D FEM model. More detailed description of the field tests is presented in papers $[10,11]$. 


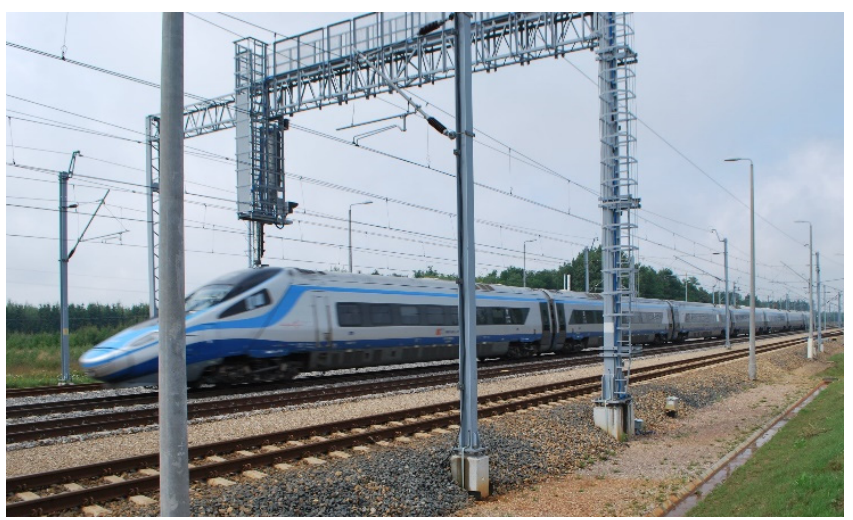

Fig. 1. The analyzed passenger train - code name Pendolino

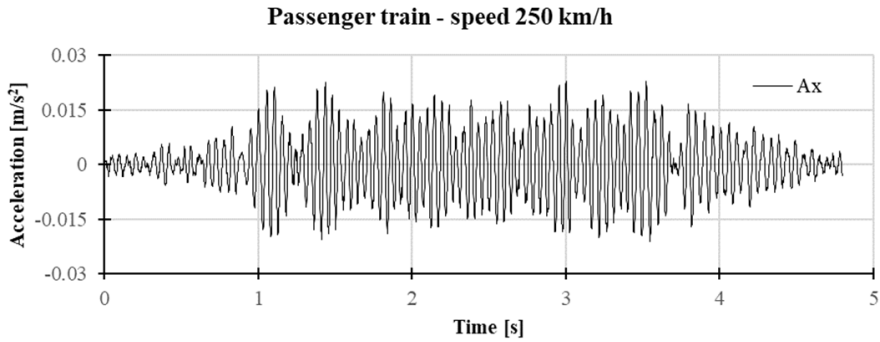

a)

Passenger train - speed $250 \mathrm{~km} / \mathrm{h}$

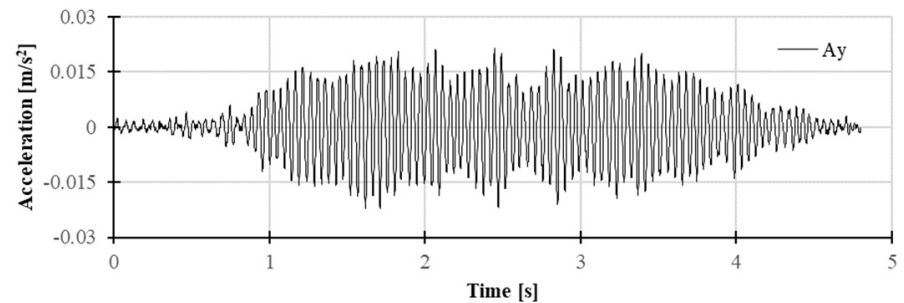

b)

Passenger train - speed $250 \mathrm{~km} / \mathrm{h}$

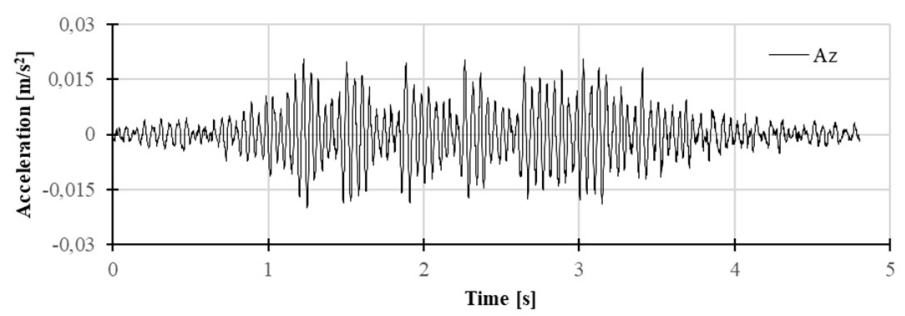

c)

Fig. 2. Vertical vibrations of accelerations on the foundation for speed $250 \mathrm{~km} / \mathrm{h}$

\section{FEM model}

A 3D calculation model based on the principles of Finite Element Method (FEM) was adopted (comp. Fig. 4). It is a typical residential building with a traditional construction. Structural elements such as beams and columns were modeled with beam finite elements (a two-node finite element with 6 degrees of freedom in the node), and surface elements such as walls and ceilings with shell elements (a four-node or three-node finite element with 6 degrees of freedom in the 
node). The partition walls in the calculation model were treated as a substitute surface load. In the model, due to very good ground conditions, full constraint was assumed in the foundation level $(T x=T y=T z=R x=R y=R z=0)$. Fig. 4 the visualization of the building's calculation model.

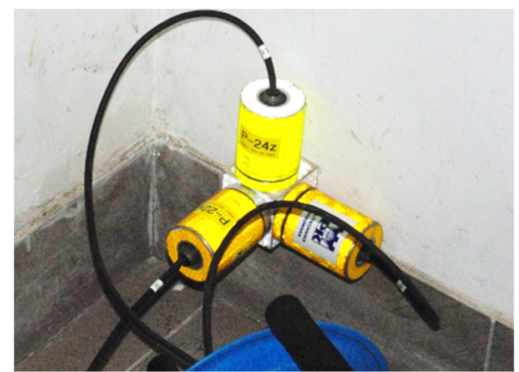

Fig. 3. Acceleration sensors mounted on the foundation of the building

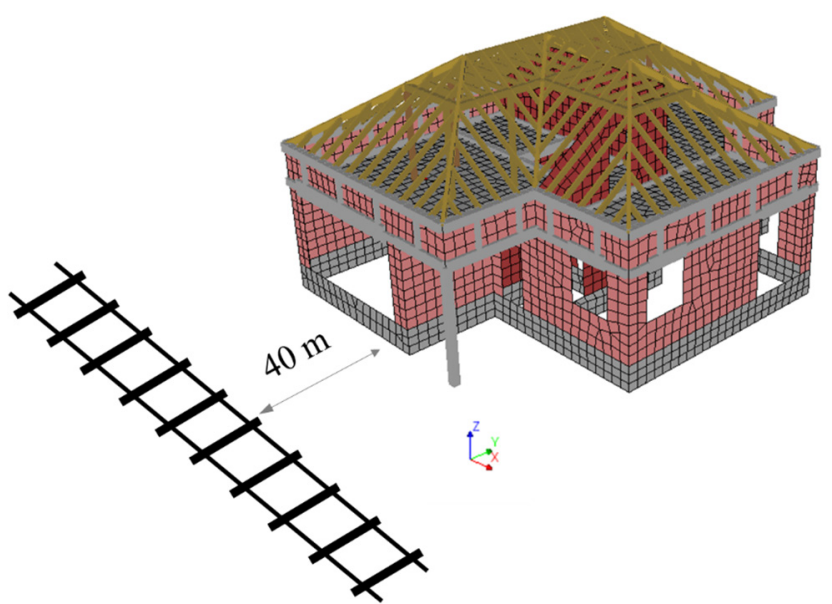

Fig. 4. 3D FEA model and it's pose relative to the railway line

For the entire structure, global damping with a critical fractional damping $5 \%$ was assumed. This corresponds to buildings with a traditional brick construction. In the calculations, dead loads and $40 \%$ of live loads were assumed. The calculations were made using the direct integration method with time step $\Delta t=0.000976 \mathrm{~s}$, which corresponds to $1024 \mathrm{~Hz}$ sampling. Kinematic loads were assumed in the form of recorded accelerations applied at the base of the model as a uniform excitation (comp. Fig. 2 as an example).

\section{Results}

Due to the structural layout and span length of monolithic ceilings in the building, the impact of vibrations on people was examined, in particular at the points specified in Fig. 5. The control points used in Fig. 5 were also used in the presentation of results. The results are presented in the form of bars on the graphs. The bars represent the RMS acceleration in one-third octave band. The lines at the graphs represents the thresholds of the comfort according to polish code [8]. The results are also presented as the WODL ratio. The WODL ratio (in English, the human vibration perceptivity ratio) [8], is the measure of vibration perception by people. It is the maximum ratio of the acceleration RMS value obtained from the analysis to the acceleration RMS value equivalent to the threshold for the perception of vibration by humans (in the same 1/3 octave band) chosen from each $1 / 3$ octave band: 
$W O D L=\max \left(\frac{a_{R M S}}{a_{z}}\right)$,

where: $a_{R M S}$ - acceleration RMS value obtained from analysis in $1 / 3$ octave band; $a_{z}-$ acceleration RMS value equivalent to the threshold for the perception of vibration in a $z$-direction in the same $1 / 3$ octave band as in $a_{R M S}$.

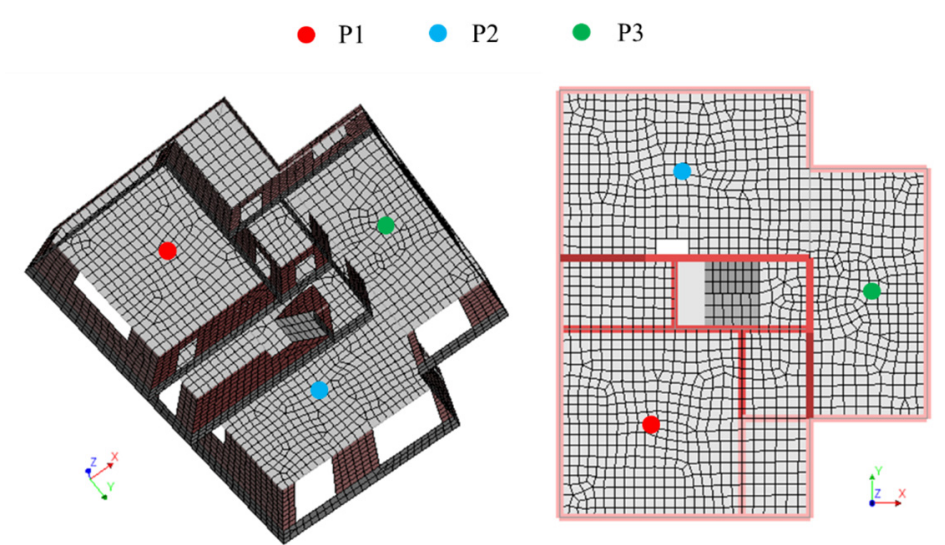

Fig. 5. Control points to examine the influence on human in the building

The selected analysis result of the influence on human in the building is presented in Fig. 6, while results for all analyzed events are presented in the Table 1 . The aggregate results for all the analyzed events are shown in Fig. 7. For the obtained results, the WODL ratio has been developed exponential lines of the trend. Trend lines have been developed in two variants: for speeds from 40 to $230 \mathrm{~km} / \mathrm{h}$ and for speeds from $40-250 \mathrm{~km} / \mathrm{h}$. A good mapping of the trend to a speed up to $230 \mathrm{~km} / \mathrm{h}$ was observed. The increase in the WODL index is has an exponential nature and it is possible to use it to predict WODL values at changes in the crossing speed of the analyzed train. At $250 \mathrm{~km} / \mathrm{h}$, a decrease in WODL ratio was observed. This is probably related to the shift in the phase of frequency excitation. In this case, analyzes are necessary for different types of buildings and different ground conditions.

Table 1. Results of the analysis - WODL ratios

\begin{tabular}{|c|c|c|c|}
\hline No. & Speed $[\mathrm{km} / \mathrm{h}]$ & Central frequency $[\mathrm{Hz}]$ & WODL $[-]$ \\
\hline 1 & 40 & 20 & 0.20 \\
\hline 2 & 80 & 16 & 0.32 \\
\hline 3 & 120 & 16 & 0.33 \\
\hline 4 & 160 & 16 & 1.60 \\
\hline 5 & 160 & 16 & 1.71 \\
\hline 6 & 200 & 16 & 3.08 \\
\hline 7 & 200 & 16 & 2.86 \\
\hline 8 & 200 & 16 & 2.60 \\
\hline 9 & 230 & 16 & 5.14 \\
\hline 10 & 230 & 16 & 5.21 \\
\hline 11 & 250 & 20 & 2.62 \\
\hline 12 & 250 & 20 & 2.72 \\
\hline 13 & 250 & 16 & 5.07 \\
\hline 14 & 250 & 20 & 2.89 \\
\hline 15 & 250 & 20 & 3.06 \\
\hline
\end{tabular}




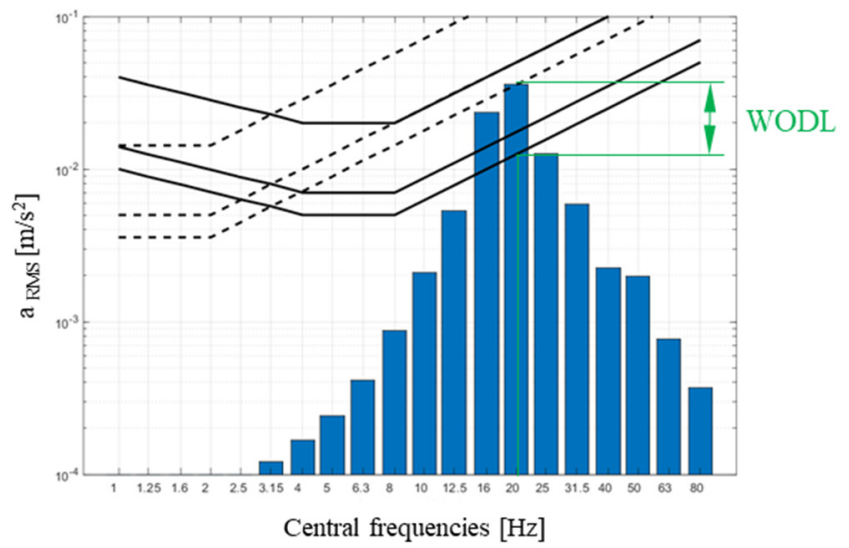

Fig. 6. Influence of vibration on human in the building according to [8]

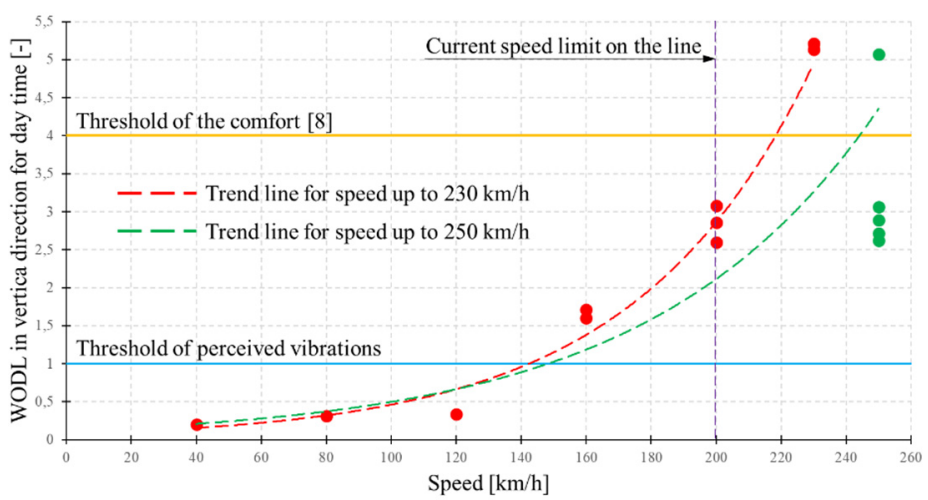

Fig. 7. WODL ratios and trend line curves for predicting the WODL ratio

\section{Conclusions}

The performed tests and analyzes indicate that in the current speed limits, the impact of vibrations on people according the code [8] is satisfied. For higher speeds, the comfort threshold was exceeded in individual cases. There is no vibro-insulation in the track construction. In the case of raising the speed up to $250 \mathrm{~km}$, it may be necessary to install vibro-insulation in the track in order to ensure the comfort for people in the buildings close to the railway line. The zones of influence of the railway lines on people in the buildings were already analyzed in the work [12]. The results presented in the above paper may be used for their development for future train speeds.

\section{References}

[1] Marioka M., Griffin M. J. Difference thresholds for intensity perception of whole-body vertical vibration: Effect of frequency and magnitude. The Journal of the Acoustical Society of America, Vol. 107, Issue 1, 2000, p. 620-624.

[2] Kowalska Koczwara A., Pachla F., Stecz P., Stypuła K., Tatara T., Lejk J., Sokolowski M. Vibration-based damage identification and condition monitoring of metro trains: Warsaw Metro case study. Shock and Vibration, Vol. 2018, 2018, p. 8475684

[3] Kowalska Koczwara A., Stypula K. A comparative analysis of two methods for determining the influence of vibrations on people in buildings. Technical Transactions, Vol. 114, Issue 1, 2017, p. 53-64.

[4] BS 6472-1:2008 Guide to Evaluation of Human Exposure to Vibration in Buildings. Part 1: Vibration Sources Other Than Blasting. British Standard, 2008. 
[5] DIN 4150-2 Structural Vibration. Part 2: Human Exposure to Vibration in Buildings. German Standard, 1999.

[6] ISO 2631-2 Guide to the Evaluation of Human Exposure to Whole Body Vibration. Part 2 - Vibration in Buildings. International Organization for Standardization, 2003.

[7] ISO 10137 Bases for Design of Structures - Serviceability of Buildings and Walkways Against Vibration. International Organization for Standardization, 2007.

[8] PN-B-02171:2017-06 Evaluation of Vibrations Influence on People in Buildings. Polish Standard, 1988, (in Polish).

[9] Zhai W., Wei K., Song X., Shao M. Experimental investigation into ground vibrations induced by very high speed trains on a non-ballasted track. Soil Dynamics and Earthquake Engineering, Vol. 72, 2015, p. 24-36.

[10] Kożuch B., Tatara T. The environmental impact of the vibration induced by the passage of trains at various speeds. Procedia Engineering, Vol. 199, 2017, p. 2693-2698.

[11] Stypula K., Tatara T. Vibrations of free-field and building caused by passages of the Pendolino train. Technical Transactions, Vol. 114, Issue 1, 2017, p. 85-100.

[12] Pachla F., Radecki Pawlik B., Stypula K., Tatara T. Vibration induced by railway traffic-zones of influence on buildings and humans. Proceedings of the 27th International Conference on Vibroengineering, Vol. 13, 2017, p. 188-192. 